\title{
COP26: This time, nurses are taking a lead.
}

\author{
Ruth McDermott-Levy, PhD, MPH, RN, FAAN, Professor \& Co-Director, Mid-Atlantic Center for \\ Children's Health and the Environment. M. Louise Fitzpatrick College of Nursing, Villanova University.
}

Cite as: McDermott-Levy, R. (2021). COP26: This time, nurses are taking a lead. Witness: The Canadian Journal of Critical Nursing Discourse, Vol 3(2), pp 6-9 https://doi.org/10.25071/2291-5796.118

When people ask me, "What does climate change have to do with nursing?", my response is: "Everything!" Our changing climate influences the current health conditions of the patients and populations we care for. This includes exacerbations of illnesses, exposures to vector-borne diseases, and equitable access to food, clean air, medical equipment, and a myriad of social supports that promote and maintain health. These multiple health impacts influence nursing practice from disaster preparation and management, the frequency and severity of illnesses of hospitalized patients, our discharge planning, and preventive and health protective actions. In fact, climate change has been identified as the greatest global public health threat (Lancet Countdown, n.d.). To promote, maintain, and restore health, nurses must be aware of basic climate science, including the causes of climate change and its health impacts. In addition, nurses must advocate at the local, province or state, national, and global levels to address climate change.

While nursing as a profession witnesses the downstream health and social impacts of the climate crisis, rarely are we invited to participate at decision-making tables regarding this shared global emergency. This year, that changed - and for the better. I was thrilled to be asked to represent the Alliance of Nurses for Healthy Environments (ANHE) at a key decision-making event, and this commentary shall present a bit of my thoughts about this experience and of the necessity that we not only be in the room, but lead key discussions, especially those regarding the health implications of environmental degradation.

At the global level, the key climate change meeting is the United Nations' (UN) Climate Change Conference of the Committee of the Parties - commonly referred to as the COP. The $\mathrm{COP}$ is a two-week long meeting. For health care professionals there is also the Global Climate and Health Summit that is sponsored by the Global Climate and Health Alliance on the Saturday between the 2-week COP sessions.

COP meetings have occurred annually (except in 2020 due to COVID-19) since 1995. Typically, those who are members of the COP are the highranking decision-making bodies of the United Nations Framework Convention on Climate Change (UNFCCC). The UNFCCC works with member nations to address climate change through efforts to stabilize greenhouse gas emissions, support ecosystems to adapt naturally, and promote sustainable development (United Nations Framework Convention of Climate Change, n.d.).

From my perspective as an observer, I would divide the UN Climate Change Conference - the COP, into four separate yet simultaneous events. The first two are "Blue Zone" events, both of 
which require official passes. The first COP event enables delegates of the Parties to meet and negotiate strategies between nations to address greenhouse gas emissions to keep the earth's average temperature below a $1.5^{\circ} \mathrm{C}$ increase from pre-industrial era global temperatures (as outlined in the Paris Agreement). The second COP event in the "Blue Zone" involves conference sessions on topics that are related to climate change, such as forestry, transportation, energy, and climate justice. This is much like a typical professional conference, albeit a very large conference. National leaders, ministers, academics, and nongovernmental organizations' (NGOs) representatives both attend and present at these "Blue Zone" conference events. The third COP event occurs in what's known as the "Green Zone." This area is open to the public and has displays and sessions that are offered by universities and NGOs. Finally, the fourth COP event is the speakers and protests that occur outside of the secure COP area. In my opinion, all four events associated with the COP are equally important to address climate change and climate action globally.

In the fall of 2018, before COP24, the Intergovernmental Panel on Climate Change (IPCC), the UN's scientific body that examines the strongest evidence to make predictions and recommendations about climate change, reported that despite previous assertions of avoiding global temperature rise of $2.0^{\circ} \mathrm{C}$, to avoid human peril, global average temperatures must remain below $1.5^{\circ} \mathrm{C}$ of pre-industrial era temperatures (IPCC, 2018). Soon after this IPCC report, the International Council of Nurses (ICN) released an updated position statement on climate change, health, and nursing, asserting that human activity was responsible for climate change and calling on nurses to engage across sectors to reduce the effects of greenhouse gases that are responsible for climate change (ICN, 2018).

With that knowledge, I headed to Katowice, Poland to attend COP24 in 2018. Without official observer status, my participation involved attending the Green Zone events and presenting at the Saturday Global Climate
Health Summit as a representative for the Alliance of Nurses for Healthy Environments (ANHE). Sadly, I was the only nurse presenting at the Global Climate and Health Summit. As I listened to my fellow presenters speak about the role of the physician in climate change, I was surprised to hear such a limited illness-based perspective to such a complex issue. In my presentation, titled, "Nurses, Climate Change \& Health: A Growing Movement," I shared the work of nurses globally in educating, researching, and serving communities impacted by climate change. I then paused and asked how many nurses were in the audience. One sole nurse raised her hand. I then shared with the audience that nurses are the largest group of licensed health professionals, where globally the ratio of nurses to physicians was 2:1 (Crisp \& Chen, 2014). I argued that if physicians want to address climate and health, they must include nurses and that we are here, ready, with much to offer.

Three years later, the IPCC (2021) issued another sobering report warning the changes in our climate are occurring more rapidly and with greater intensity and that fossil fuels are directly responsible for the change. A few weeks later, the Lancet Countdown reported that our current national greenhouse gas commitments would place the world not at a $1.5^{\circ} \mathrm{C}$ increase, but at a $2.4^{\circ} \mathrm{C}$ average global temperature increase (Watts et al, 2021).

Between Oct $31^{\text {st }}$ and November $12^{\text {th }}, 2021$, approximately 30,000 people representing over 200 countries attended COP26 in Glasgow Scotland. This time, two other nurses and I were among the official COP observers, again there representing the ANHE but this time with full access to both the Blue and Green Zones. This time, a greater sense of urgency among most of the diplomats, observers, and people we spoke with outside the COP facilities was palpable. This time, health was finally addressed formally at the COP, highlighting it as a crucial factor that is impacted by climate change. This time, the World Health Organization had a pavilion with health-related presentations, and there was a "Health Day" during the COP conference. This time, instead of only a few nurses present at the 
COP and its' related activities, nurses from the Alliance of Nurses for Healthy Environments and the International Council of Nurses collaborated to present at the WHO pavilion about nurses' leadership in influencing healthrelated conversations associated with climate change. Nurses were also represented in the Green Zone as ANHE nurses presented the Nurses' Climate Justice Agenda (ANHE, 2021). And this time, nurses and other health professionals marched outside of the official COP area to bring awareness to the human health impacts of climate change.

The outcome of COP26 was not as strong as many of us had hoped, but advances were made. The Glasgow Climate Pact included a phasing out of coal power; over 100 nations pledged to reduce methane emissions by $30 \%$, and more than 130 nations agreed to stop and reverse deforestation by 2030 (Hill \& Babin, 2021). Additionally, 50 countries, including the UK and the US, signed-on to support climate-resilient and low-carbon health systems as part of the COP26 Health Programme (World Health Organization, 2021). As an observer at COP26, I was able to hear from national officials, NGOs, and climate activists from around the world about the potential implications of the decisions made at COP26. For example, changes in forests and the expectation to re-forest areas can influence a family's ability to farm and could subsequently drive students out of school and into work to support their families. Further, national requirements related to reforesting through tree planting programs could influence indigenous peoples' land rights.

\section{References}

Alliance of Nurses for Healthy Environments (2021). Climate justice agenda for nursing. https://envirn.org/climate-change/climatejustice-agenda-for-nursing/

Crisp, N., \& Chen, L. (2014). Global supply of health professionals. The New England
As nurses, we understand the impact of inequities related to income, education, environment, and culture upon the health of populations, and we understand further that the health impacts of climate change are also about inequity. We work in complex health systems and are perfectly situated to propose methods to reduce fossil fuel-based energy use and foster increased climate adaptation and resilience. Our knowledge and skills are needed to address the complexity of climate change solutions. We see the downstream impacts of upstream structural decisions. As a profession, we are witnesses to the health impacts of climate change on our patient populations.

By virtue of all that we witness and all that we understand, we have an important role to play in identifying the health impacts on our patients, collaborating with other health care professionals and taking leadership in climate action. We can create and translate the science of climate change and make those links between health and our changing environment for others. We must be part of the climate and health discussions and continue to engage on the local, province/state, national, and global levels. Because this IS the time that we must lead on climate action and be there to address, mitigate, and collectively solve this global public health emergency that is climate change.

The author identifies no conflicts of interest, need for ethical clearance nor funding associated with the development of this invited commentary.

Journal of Medicine, 370(23), 2247-2248. https://doi.org/10.1056/NEJMc1404326

Hill, A. \& Babin, M. (2021). What COP26 did and didn't accomplish. Council on Foreign Relations. https://www.cfr.org/inbrief/cop26-climate-outcomes-successesfailures-glasgow 
Intergovernmental Panel on Climate Change, 2021: Summary for Policymakers. (2021)

In V. MassonDelmotte, P. Zhai, A. Pirani, S.L. Connors, C. Péan, S. Berger, N. Caud, Y. Chen, L. Goldfarb, M.I. Gomis, M. Huang, K. Leitzell, E. Lonnoy, J.B.R. Matthews, T.K. Maycock, T. Waterfield, O. Yelekçi, R. Yu, \& B. Zhou (Eds.), Climate change 2021: The physical science basis. Contribution of Working Group I to the sixth assessment report of the Intergovernmental Panel on Climate Change. Cambridge University Press.

Intergovernmental Panel on Climate Change. (2018). Summary for Policymakers. In V. Masson-Delmotte, P. Zhai, H.-O. Pörtner, D. Roberts, J. Skea, P.R. Shukla, A. Pirani, W. Moufouma-Okia, C. Péan, R. Pidcock, S. Connors, J.B.R. Matthews, Y. Chen, X. Zhou, M.I. Gomis, E. Lonnoy, T. Maycock, M. Tignor, \& T. Waterfield (Eds.), Global Warming of $1.5^{\circ} \mathrm{C}$. World Meteorological Organization. Available https://www.ipcc.ch/sr15/

International Council of Nurses. (2018). Position statement: Nurses, climate change and health. https://www.icn.ch/sites/default/files/inline files/ICN\%20PS\%20Nurses $\% 252 \mathrm{c} \% 20 \mathrm{cli}$ mate\%20change\%20and\%20health\%20FI NAL\%20.pdf

Lancet Countdown (n.d.). The Lancet Countdown on health and climate change. https://www.thelancet.com/countdownhealth-climate/about

\section{United Nations Framework Convention of} Climate Change (UNFCCC) (n.d.). About the Secretariat. https://unfccc.int/about-us/about-the$\underline{\text { secretariat }}$

Watts, N., Amann, M., Arnell, N., AyebKarlsson, S., Beagley, J., Belesova, K., Boykoff, M., Byass, P., Cai, W., CampbellLendrum, D., Capstick, S., Chambers, J.,
Coleman, S., Dalin, C., Daly, M., Dasandi, N., Dasgupta, S., Davies, M., Di Napoli, C., Dominguez-Salas, P., ... Costello, A. (2021). The 2020 report of The Lancet Countdown on health and climate change: responding to converging crises. The Lancet (London, England), 397(10269), 129-170. https://doi.org/10.1016/S01406736(20)32290-X

World Health Organization. (9 November, 2021). Countries commit to develop climate-smart health care at COP26 UN climate conference.

https://www.who.int/news/item/09-112021-countries-commit-to-developclimate-smart-health-care-at-cop26-unclimate-conference 